\title{
Vida de Adil. Una creación del Laboratorio Escénico: Universo Inestables
}

\author{
Cuarta Pared, Madrid \\ Festival Essencia, 22 y 23 de diciembre de 2018
}

Espacio Teatro Contemporáneo (ETC) de creación escénica de la sala teatral Cuarta Pared planteó su convocatoria del año 2018, Universo Inestables, en torno a numerosos interrogantes relacionados con la dificultad de planificar una vida cuando la inestabilidad y la imprevisibilidad rigen nuestro día a día, lo efímero e intercambiable, la precariedad y la incertidumbre marcan nuestra vida laboral, social, y afectiva.

La premisa para esta convocatoria abierta a todo tipo de creadores escénicos fue partir de una «historia de vida» y se planteó investigar cómo una temática común puede dar origen a diversas propuestas escénicas según los lenguajes explorados. En qué medida el tipo de lenguaje escogido potencia aquello que queremos contar, explorando así la palabra en relación a diferentes tipos de lenguajes teatrales y otros ajenos a este, y reflexionar acerca de su hibridación.

La historia de vida de Adil es la de un camino marcado por la inestabilidad. Se nos presentó la posibilidad de acercarnos a ese universo, honrarlo, y plasmar escénicamente sus vivencias. Experiencias como las de Adil nos permiten ampliar la mirada respecto a la vida y su dimensión más cruda. Crueldad imperante en millones de personas que, con diferentes escenarios geográficos, culturales, políticos y sociales, parecen tener un mismo marco nefasto, «las condiciones del mercado", que desencadenan una serie de consecuencias trágicas a la hora de reunir «las condiciones necesarias» para tener una vida «estable».

El tema fundamental aquí es el "destino negro» y sus constantes en forma de penalidades que abocan a la huida y a la búsqueda de un lugar que permita hacer una vida normal, estable, en paz. El protagonista no consigue eludir su destino, y de ahí su conflicto -el intento de huir de este, y de las fuerzas políticas y sociales-. Así es el mundo de la Vida de Adil, y el cuerpo como certeza de un camino marcado por el sufrimiento.

Si pensamos en el cuerpo como territorio importante en el que se construye una identidad junto al pensamiento de una cultura o sociedad, y este a su vez sirve como escenario para la expresión de las nociones de persona-sociedad, la instalación escultórica figurativa de David González-Carpio Alcaraz compuesta por tres instalaciones de cuerpos esculturas de rasgos humanos resultó ser el lenguaje idóneo junto al texto, al movimiento, y al instrumento en vivo para el desarrollo de esta propuesta. Las esculturas de González-Carpio sugieren numerosos significados y roles, y emiten una infinidad de mensajes. Los lenguajes escogidos se complementan creando un mapa de comunicación en donde los ejes de emociones, sensaciones y acciones se articulan y relacionan.

Con los pasajes más significativos de la historia de Vida de Adil se crearon diferentes cuadros temáticos que componen el recorrido, y aunque la creación de las esculturas, en parte, fue previa a la pieza teatral parecen sacadas del propio relato de Adil. Estas dan cuenta de la fuerza y la debilidad, representan el cuerpo como palabra, el cuerpo como acción, el cuerpo escultórico como la prolongación del cuerpo del actor. La enfermedad, el sufrimiento, el dolor, la vejez, el cuerpo representante del alma desgastada, exhausta, desesperanzada; los cuerpos de pie con vida y los cuerpos tendidos sin vida.

Esta lucha y tenaz supervivencia se conciben a través de las huellas impresas en los cuerpos maraña de células invisibles y carentes de órganos. Las figuras de la serie «Regime of a ruin" pertenecen a una instalación de dos volúmenes exentos e independientes $(1,90 \mathrm{~cm}$ de altura), de alambre policromado de color naranja óxido, que se sustentan sobre sí mismas sin necesidad de anclajes, sujeciones, ni cualquier otra pre-instalación. Inicialmente pensadas para disponerlas enfrentadas, participan en este recorrido escénico y su disposición varía según el cuadro de la historia. Los dos volúmenes, el Hombre entero y el Hombre consumido son el hombre fuerte y el hombre débil, el opresor y el oprimido, el que persigue y el que huye. Representar el azar, la estabilidad y la inestabilidad, el espejo y el reflejo, pasividad, inercia, o simplemente son testigos silentes de la vida [1]. 


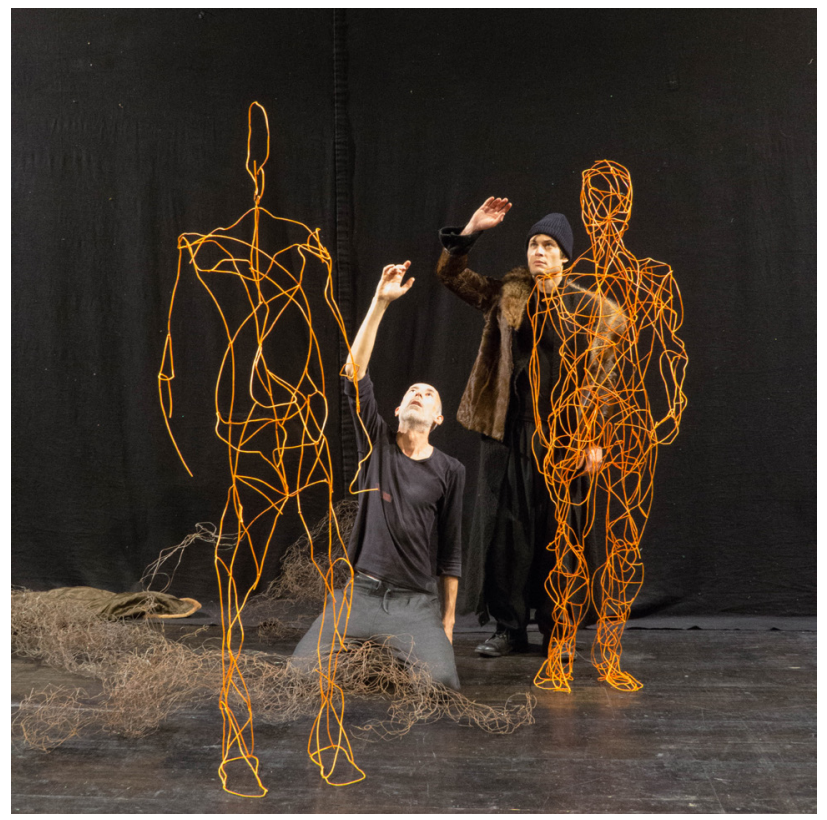

La serie «Náufragos-crecer para naufragar», tres figuras fragmentadas en escala natural (190 cm altura), de alambre recocido de $6 \mathrm{~mm}$ de diámetro, soldadura MIG y pintura acrílica es una instalación compuesta por partes y fragmentos del cuerpo que aluden a los cuerpos heridos después de la batalla, a los restos de cuerpos, a los cuerpos fragmentados, al territorio y su parcelación. Son cadáveres, cuerpos mutilados, cuerpos objetos sin vida.

La serie "Maleables» inspirada en la instalación «Urdimbres», son tres figuras de escala natural $(1,75 \mathrm{~cm}$ altura), de alambre de 1,3 milímetros de diámetro de color gris.

Interactúan del mismo modo que las esculturas de «Regime of a ruin» con los intérpretes y proporcionan una sintaxis visual que enriquece y complementa al relato. Cuerpos maleables en ocasiones sirven de extensión del cuerpo del actor, y en otras, son cuerpos con o sin vida, pasivos, inertes, cuerpos castigados, cuerpos cansados, o simplemente representan el peso de un cuerpo.

La extensión libre del espacio escénico acerca al público el cuerpo del actor y el cuerpo escultórico, y exige una sensibilidad especial al movimiento preciso y limpio de los actores. El cuerpo escultórico de la figura se imprime en el cuerpo del actor y construye el gesto y el movimiento de la gramática corporal de modo que el hombre entero se vuelve

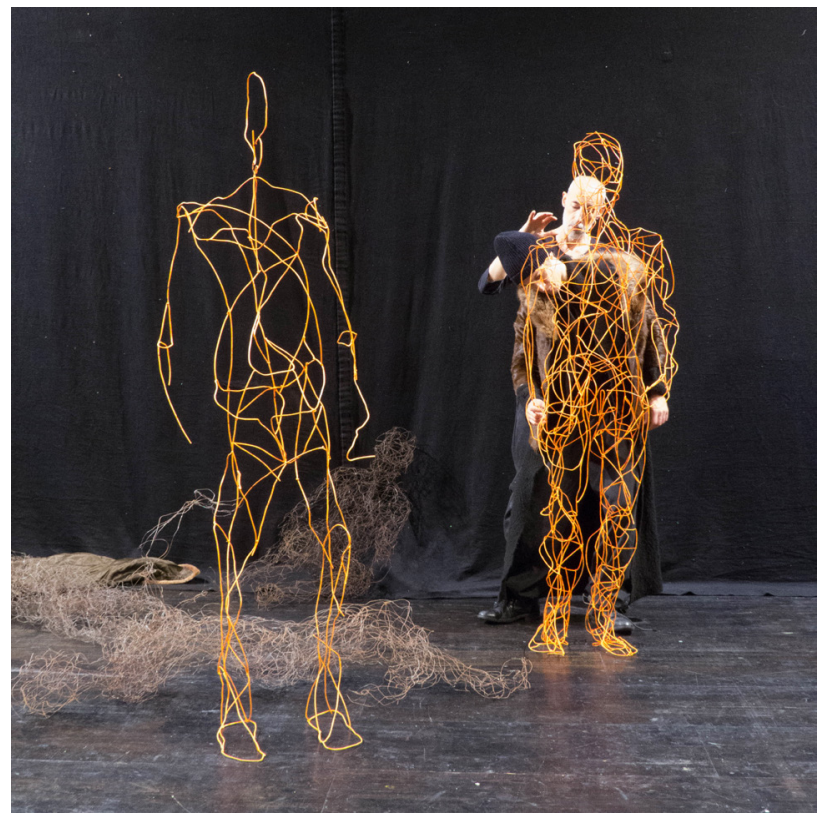

un cuerpo racional, pensante, enérgico, sensible. El cuerpo desgastado, se torna cuerpo psíquico, parafraseando a David Le Breton, cuerpo simbólico, el cuerpo que metaforiza lo social, cuerpo emocional de un individuo desgastado emocional y físicamente.

El cuerpo escultórico del actor y la escultura figurativa se unen en el punto de indistinción -la figura se convierte en un cuerpo vivo, y el cuerpo vivo en un cuerpo maraña-. Este juego de reducir un personaje a su cuerpo y posteriormente a una figura, escultura inmóvil, nos lleva a pensar en la desmaterialización del ser como reacción a los procesos de consumo de la sociedad capitalista, y a su vez en la resultante de esos procesos relacionados con el verbo reflexivo consumirse. Las personas y cuerpos que acaban consumidos en un sistema de producción y consumo que reduce los seres a números.

De este modo, Adil se va consumiendo en el camino, y su alma consumida por dificultades, pena, cansancio, desilusión, desesperanza, falta de reconocimiento, la imposibilidad de encontrar un camino seguro, y otros tantos avatares, se va desmaterializando y reduciendo a un cuerpo -desalmado, desarmado para la vida-; no hay más que siluetas, almas muertas en cuerpos inertes en escena. Esos cuerpos inertes nos remiten a los cuerpos escultóricos de la instalación. 


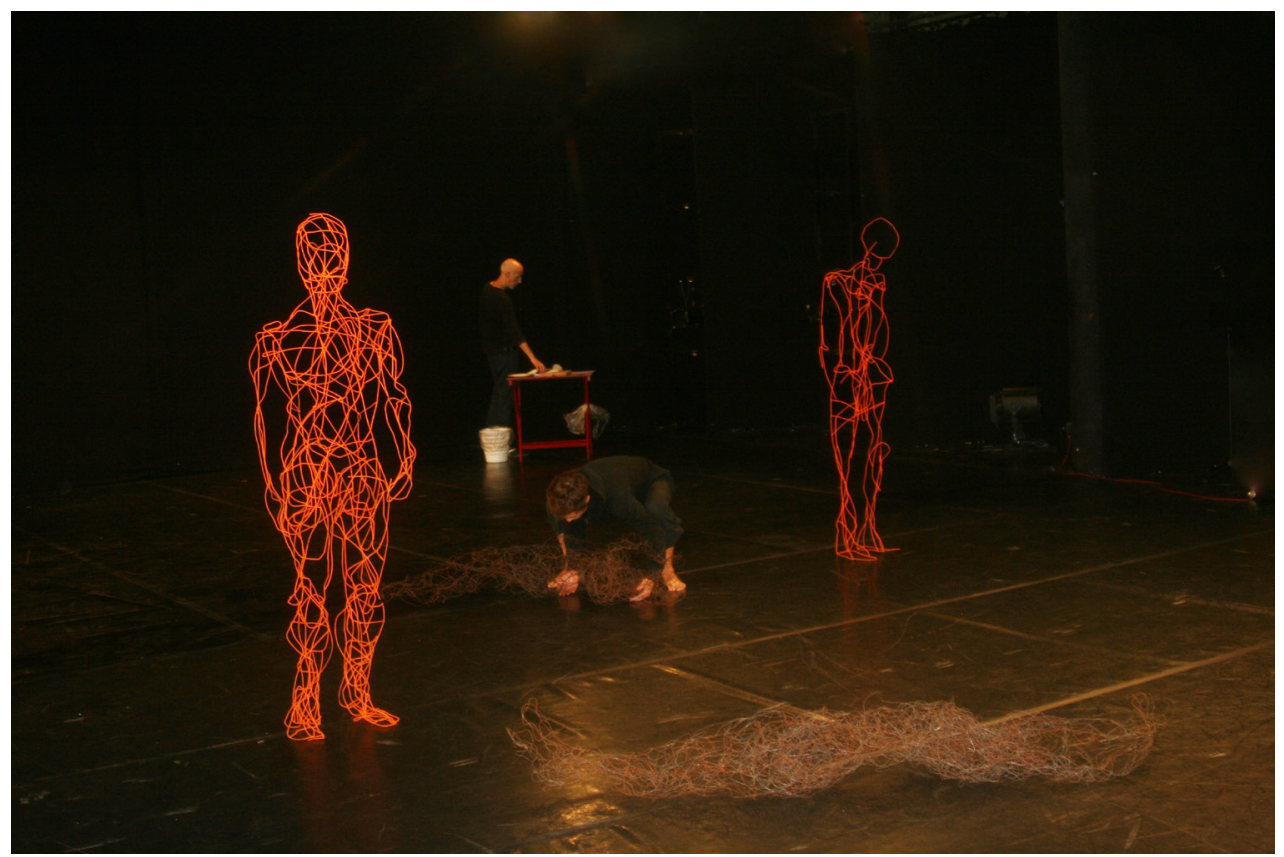

El diálogo con el instrumento y el universo sonoro que este crea nos revela el cuerpo del actor tensado condicionado al movimiento y al gesto sumido en la emoción. Dentro de este contexto se establece una resonancia entre el cuerpo del actor y escultórico. En la relación y manipulación de las figuras existe resistencia, prolongación, y afección. De ese diálogo nace una narrativa que va más allá de la ilustración. El cuerpo del actor por momentos se funde con las esculturas para deformar, deconstruir, y simbolizar.

Si el arte se puede ver como simulacro de la vida, podemos pensar en el objeto del arte como la metáfora simbólica de la vida del ser humano, que a su vez, nos lleva a pensar en la materia y su vida en el arte. En los últimos cien años creamos, en el mundo occidental, una riqueza material mayor que la de ninguna otra sociedad en la historia de la especie humana. Los procesos de consumo y de intercambio comercial resolvieron transformar al arte en un producto regido por la oferta y la demanda. Sintomáticamente, la materialidad de la obra de arte pasó de una consistencia sólida, resistente, permanente, a una apariencia líquida, frágil, no permanente. Aquí podemos transponer la idea de la materialidad de la obra escultórica con la materialidad del ser que, en determinadas circunstancias de vulnerabilidad, pasa de una consistencia sólida, resistente, permanente a una apariencia frágil, inesta- ble. Si el objeto del arte es la metáfora simbólica de la vida del ser humano, el cuerpo de la persona y de la escultura se unen para transmitir esta idea en la pieza.

Una exhaustiva revisión del material físico conduce hacia los contextos del devenir, del azar, del consumo, del tiempo y del espacio, aspectos cada vez más importantes en la cultura occidental, y por su influencia, en la global. La producción nómada, transitoria de la escultura le confiere un carácter procesual, relacionado con la temporalidad, y encuentra eco en la propia finitud de la vida y en la levedad de la existencia.

El público situado en el espacio escénico nos remite a la cercanía y al espacio común. Se plantea una mirada fragmentada en una mayor variedad de perspectivas. Esta podría ser una evocación del quimérico inalcanzable concepto de Aleph en Borges.

En la retórica del cuerpo un fragmento puede referir la totalidad o, por el contrario, nos puede hablar de cuerpos despedazados, real o simbólicamente. El cuerpo se vuelve parcelación y territorio como los pies «miembros privilegiados» que «ponían en marcha registros olvidados por un occidente que los invisibiliza, los calla y los niega» que María Teresa Hincapié, la artista colombiana, rescataba en su búsqueda del poder que da caminar, y así se convirtió en una 
caminante de la eternidad, una nómada. Adil, el caminante, el nómada de la vida no ha dejado de caminar.

Para el trayecto de la pieza se estableció una diagonal espacial y temporal -un camino de idas y vueltas de diferentes dimensiones temporales-. En la diagonal conviven los elementos de la espacialidad existencial, el aquí y el allí, el pasado, el presente y el futuro.

En la diagonal espacial prima el Universo, tanto un universo conceptual de inestabilidad, como el universo del cielo estrellado, un único lugar de paz anhelado por Adil. Las esculturas conviven en este espacio con los actores, y su recorrido varía en función de los cambios que suceden en el plano general. En el comienzo de la pieza, las esculturas de la serie «El régimen de la ruina» se sitúan en la diagonal que termina con el espacio cerrado de la cocina. El Hombre entero no está en el campo visual del público que entra en la sala. A medida que el público se adentra en ella, esta figura sorprende con su presencia robusta, emergiendo detrás de una columna.

Esta escultura que en ocasiones alude a la fuerza, integridad, equilibrio del hombre entero, fuerte y sereno, en otras, toma el papel del opresor, encarnando las conductas y comportamientos crueles y destructivos presentes en nuestra sociedad, y de la violencia institucional. A su vez, la figura solitaria de Hombre consumido o esqueleto representa el deterioro de la vida de un hombre que acaba arrinconado y encerrado en el espacio angosto de la cocina de un apartamento alquilado que tiene que dejar.

Estos cuerpos objetos mecanizados, animados, y los cuerpos marionetas vivos, son portadores de los síntomas de nuestra época. Son magnificados con el juego de luz que crea sombras gigantescas y los potencia. Tienen la función de alarmar y hacer reflexionar acerca de nuestra sociedad y sus lacras. El ser y la existencia son representados en y por la forma figurativa, y sería muy interesante seguir investigando acerca de la manifestación física de la materialidad y su desintegración -acerca del cuerpo fuerte frente al cuerpo consumido, acerca del cuerpo como campo de batalla, y la unión entre cuerpo individuo y cuerpo sociedad de Le Breton, acerca del cuerpo como símbolo conductor de conceptos sociales-. Continuar profundizando en ese umbral que es el cuerpo, intentando comprender el sentido de ese mundo que, cual destino negro, pareciera llevarnos inevitablemente a la consumación.

\section{Angelina Mrakić David Hernández Vargas} Universidad Complutense de Madrid 